\title{
Genital Rhabdomyoma
}

National Cancer Institute

\section{Source}

National Cancer Institute. Genital Rhabdomyoma. NCI Thesaurus. Code C6517.

A rare benign skeletal muscle neoplasm arising from the female genital tract. It is characterized by the presence of small nucleated rhabdomyoblasts within a fibrous and myxoid stroma. 